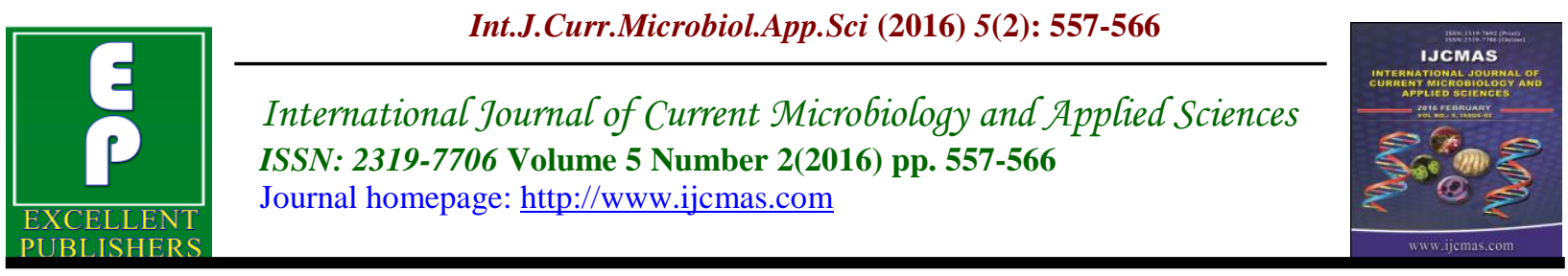

Original Research Article

doi: http://dx.doi.org/10.20546/ijcmas.2016.502.063

\title{
Genetic Purity of Flue Cured Tobacco F1 Hybrid with RAPD Markers
}

\author{
D. Satish Kumar* and D. Kalyani \\ School of Life and Health Sciences, Adikavi Nannaya University, Rajah Rajah Narendhra Nagar, \\ Rajamahendravaram, Andhra Pradesh 533296, India \\ *Corresponding author
}

\begin{tabular}{|c|c|}
\hline & A B S T R A C T \\
\hline $\begin{array}{l}\text { Ke y w or d s } \\
\text { Genetic purity, } \\
\text { Tobacco hybrids, } \\
\text { RAPD, GOT, } \\
\text { Seed lots, } \\
\text { off types. }\end{array}$ & $\begin{array}{l}\text { Tobacco (Nicotiana tabacum) crop is grown for its leaves and it is covered in an } \\
\text { area of } 4 \text { million hectares in } 125 \text { countries. India is the second largest producer of } \\
\text { tobacco and is grown in different states. In India Flue Cured Virginia (FCV) and } \\
\text { non-flue cured tobacco varieties were cultivated. Genetic purity in hybrid tobacco is } \\
\text { the major constraint. Twenty RAPD primers were used to identify the tobacco } \\
\text { parents and its F1 hybrid out of twenty RAPD's, three primers (OPA-5, OPA-7 and }\end{array}$ \\
\hline Article Info & $\begin{array}{l}\text { OPB-9) were amplified specific to male parent, female parent and its F1 hybrid } \\
\text { OPA-7 primer showed polymorphism for male parent, female parent and its hybrid. }\end{array}$ \\
\hline $\begin{array}{l}\text { Accepted: } \\
\text { 26 January } 2016 \\
\text { Available Online: } \\
\text { 10, February } 2016\end{array}$ & $\begin{array}{l}\text { Fifty seed lots (1-50) were tested with OPA-7 primer and found a few off types in } \\
\text { the three seed lots. The genetic purity in seed lot- } 6(\mathrm{~S}) \text { is } 97 \% \text {, seed lot-14 (T) is } \\
96 \% \text { and seed lot-31 (U) is } 98 \% \text {. The cost effective field grow out trials (GOT) were } \\
\text { replaced by this RAPD analysis and the results were obtained in less time. }\end{array}$ \\
\hline
\end{tabular}

\section{Introduction}

Tobacco (Nicotiana tabacum) is an important commercial annual crop grown in India of $0.45 \mathrm{M}$ ha area (Anonymous CTRI website 2015). It produces $800 \mathrm{M} \mathrm{kg}$ of tobacco leaf annually and ranks third position worldwide. Indian tobacco accounts for $10 \%$ of the area and $9 \%$ of the total production in the global scenario (Anonymous Tobacco board website 2015). Flue Cured Virginia tobacco (FCV) is the high yielding variety and has major share in Indian exports. It belongs to Solanaceae family and it is allotetraploid with $4.5 \mathrm{~Gb}$ genome size (Nicolas et al., 2014).
The chromosome number of $N$. tabacum is $2 n=4 x=48$. Tobacco is a self pollinated plant. Now-a-days in hybrid seed production breeders are using established CMS (Cytoplasmic Male Sterility) system to avoid time consuming emasculation in heterosis breeding (Patrick and Roger, 1998; Liu et al., 2007a). The CMS (Cytoplasmic Male Sterility) female parent was unable to produce functional pollen so it is a male sterile. The Tobacco hybrid was developed from male sterile line (A line) and their cognate iso-nuclear maintainer line (B line). The Genetic purity in hybrids of specific 
combination is very important aspect in commercial hybrid seed production to satisfy farmer, seed certify agencies, variety registration system and for plant variety and farmer's rights (PVP\&R) protection. There is a chance of mixture of other seeds in that seed lot or out crossing is possible and it is also very important to identify or characterize both the parents and hybrid. Generally in hybrid seeds genetic purity was tested by GOT (field grow out test). The GOT can be done by raising the parents and their hybrids in replicated trials and in that morphological characterization can be done based on DUS (Distinctness, Uniformity and Stability) testing, which is time consuming for field trials and required expensive labour (Ballester and de Vicente, 1998; Dongre and Parkhi, 2005). With the invention of new technologies like molecular marker development, crop improvement activities like hybrid identification, parental characterization, QTL mapping, etc., can be possible with accurate results in fewer generation breeding cycle and requires less labour. There are different molecular markers that were commonly used for genetic purity test i.e., Restriction Fragment Length Polymorphism (RFLP) (Joseph et al., 1998), Randomly Amplified Polymorphic DNA (RAPD) (Sangeeta et al., 2011; Sayyed et al., 2009; Man and Joo, 2009; Abdel et al., 2006; Ashok et al., 2011; Liu et al., 2007a, b), Amplified Fragment Length Polymorphism (AFLP) (Grzebelus et al., 2001), Simple Sequence Repeats (SSR) (Ashok et al., 2011; Abdel et al., 2006; Liu et al., 2007a \& b), Inter Simple Sequence Repeats (ISSR) (Ashok et al., 2011; Liu et al., 2007a \& b), Sequence Related Amplified Product (SRAP) (Liu et al., 2007a) and Single Nucleotide Polymorphism (SNP) (Wan et al., 2014). From the above markers RAPD is cost effective and fast result oriented molecular marker. There are less findings regarding genotype specific marker identification with RAPD in tobacco. RAPD analysis was done by arbitrary primers for determining the DNA polymorphism. RAPD is a dominant and does not require target DNA sequence of that organism. It was developed by Welsh and McClelland (1990). RAPDs are randomly distributed throughout the genome and are very high genomic abundance (Kumar et al., 2009). RAPD markers are useful in plant breeding, seed production and seed testing programs (Mc Donald et al., 1994; Del et al., 2000). In the present study we have used RAPD markers to identify the parents and hybrids of Tobacco to test genetic purity in seed lots.

\section{Materials and Methods}

\section{Plant Materials}

The pure seeds of flue cured tobacco (FCV) F1 hybrid and its parental lines were obtained from M/s ITC Ltd., ABD-ILTD, Rajahmundry. The seeds were germinated in petriplate contains moist filter paper and maintained in tissue culture room (Sarala and Rao, 2008). In the case of F1 hybrid seed lots (viz., seed lot 1-50) random seed samples were taken for the genetic purity test.

\section{DNA Extraction}

The genomic DNA was isolated from young tobacco leaves according to Doyle and Doyle (1990) with minor modifications, and concentration was estimated through Nanodrop 2000 spectrophotometer and quantified on $0.8 \%$ agarose gels. The DNA was diluted to $25 \mathrm{ng} / \mu \mathrm{l}$ for PCR analysis.

\section{RAPD PCR Assay}

The PCR analysis was done according to Williams et al (1990) with minor 
modifications. Twenty random decamer primers (Operon Technologies Inc., USA) viz. OPA-01, OPA-02, OPA-03, OPA-04, OPA-05, OPA-06, OPA-07, OPA-08, OPA09, OPA-10, OPB-01, OPB-02, OPB-03, OPB-04, OPB-05, OPB-06, OPB-07, OPB08, OPB-09 and OPB-10 were used for the identification of both the female and male FCV tobacco parents and its F1 hybrid (Table 1). The polymerase chain reactions (PCR) were performed in a $25 \mu \mathrm{L}$ mixture containing $25 \mathrm{ng}$ of genomic DNA, 2 Units Taq polymerase (Bangalore Genei Pvt., Bangalore, India), 0.2 $\mu \mathrm{M}$ RAPD decamer primer, $0.20 \mathrm{mM}$ dNTPs, $10 \mathrm{X}$ assay buffer and $2.5 \mathrm{mM} \mathrm{MgCl}$. Amplifications were performed on thermal cycler (BIORAD DNA Engine). The amplification was standardized as initial denaturation temperature $95^{\circ} \mathrm{C}$ for 5 minutes, followed by 35 cycles of denaturation at $95^{\circ} \mathrm{C}$ for 1 minute, primer annealing at $37^{\circ} \mathrm{C}$ for 1 minute, primer extension at $72^{\circ} \mathrm{C}$ for 2 minutes and a final primer extension at $72^{\circ} \mathrm{C}$ for 5 minutes. Amplified product was loaded into $1 \%$ agarose gel electrophoresis and stained with $0.5 \mathrm{mg} / \mathrm{ml}$ ethidium bromide and gel pictures were captured under UV light. The bands were scored as 1 for presence and 0 for absence respectively.

\section{Results and Discussion}

Ten polymorphic bands were scored for the F1 hybrid and its parents screening with RAPD markers. Out of twenty RAPD primers, three primers (OPA-5, OPB-9 and OPA-7) produce specific bands for female parent, male parent and F1 hybrid. These three primers were polymorphic. The primer OPA-5 produced five bands at $375 \mathrm{bp}, 625$ bp, $870 \mathrm{bp}, 1400 \mathrm{bp}$ and $2000 \mathrm{bp}$ positions, within this primer 1400 bp and 625 bp size alleles were detected as polymorphic bands. In the primer OPA-5, the 1400 bp band was amplified in both male parent and hybrid but it fails to amplify in female parent, unlike this 625 bp band was amplified in female and failed to amplify in both male parent and hybrid. This primer is specific to female parent and it can be useful for the identification of female parent (Figure 1). The primer OPB-9 amplified eight bands at 450 bp, 510 bp, 620 bp, 650 bp, 800 bp, 925 bp, $1000 \mathrm{bp}$ and $1200 \mathrm{bp}$ positions, this primer showed amplification specific to male parent. The primer OPB-9 showed polymorphic bands at $510 \mathrm{bp}, 650 \mathrm{bp}, 620$ bp, 800 bp, 1000 bp and 1200 bp length. In primer OPB-9, the fragments of $1200 \mathrm{bp}$, $800 \mathrm{bp}, 650 \mathrm{bp}$, and $510 \mathrm{bp}$ were amplified only in male parent but others fails to amplify at that position. The primer OPB-9 can be useful for the identification of male parent (Figure 2). The results of primer OPA-7 amplification showed four bands at $375 \mathrm{bp}, 550 \mathrm{bp}, 950 \mathrm{bp}$ and $1100 \mathrm{bp}$ positions, out of four bands two polymorphic bands were detected at $550 \mathrm{bp}$ and $950 \mathrm{bp}$. In primer OPA-7, $550 \mathrm{bp}$ was amplified in both male parent and hybrid but female parent fails to amplify and it is a female parent specific band. The $950 \mathrm{bp}$ size allele in OPA-7 primer was amplified in both female parent and hybrid, but fails to amplify male parent and it is a male parent specific band (Figure 3). In the primer OPA7 all the alleles amplified in both parents were amplified in F1 hybrid and this primer is suitable for detection of both parents and its hybrid. These RAPD markers were analyzed twice for confirmation of nonspecific amplification. The RAPD primer OPA-7 can detect parents and hybrid in early seed stage itself, that will reduce the cost for field planting of offspring and their evaluation by grow out test.

\section{Scanning of FCV Hybrid Seed Lots with Identified RAPD Markers}

The primer OPA-7 was used for screening 
of F1 hybrid seed lots (Seed lot 1-50). The randomly selected seedlings of FCV hybrid seed lots (100 plants) were screened with OPA-7 primer. In Seed lot-6 (S) three off type seedlings were detected (off type plants-S51, S87 and S89), which fails to amplify band at 1100 bp (Figure 4). The genetic purity of hybrid seed lots was calculated as number of off type seedlings to number of seedlings tested.

Number of off type seedling

Number of seedlings tested X 100

Out of hundred hybrid seedlings three were fail to amplify the band at $1100 \mathrm{bp}$. The percentage of genetic purity in seed lot-6 was 97\%. Similarly in Seed lot-14 (T) hundred hybrid plants were tested with OPA-7 RAPD primer, out of hundred, four seedlings were fail to amplify the specific band at $1100 \mathrm{bp}$ (off type plants-T20, T28, T62 and T100) (Figure 5). Then the percentage of genetic purity in Seed lot-14 was $96 \%$. Similarly in Seed lot-31 (U) out of hundred seedlings tested with OPA-7 RAPD primer two seedlings fails to amplify the specific band at 1100 bp (off type plantsU17 and U32) (Figure 6). The genetic purity in Seed lot-31 was $98 \%$.

Table.1 RAPD Primer Sequences

\begin{tabular}{ll}
\hline $\begin{array}{l}\text { Primer Name } \\
\text { OPA-01 }\end{array}$ & $\begin{array}{l}\text { Primer sequence } \\
\left(5^{\prime}-3^{\prime}\right)\end{array}$ \\
CAGA-02 & TGCCGAGCTC \\
OPA-03 & AGTCAGCCAC \\
OPA-04 & AATCGGGCTG \\
OPA-05 & AGGGGTCTTG \\
OPA-06 & GGTCCCTGAC \\
OPA-07 & GAAACGGGTG \\
OPA-08 & GTGACGTAGG \\
OPA-09 & GGGTAACGCC \\
OPA-10 & GTGATCGCAG \\
OPB-01 & GTTTCGCTCC \\
OPB-02 & TGATCCCTGG \\
OPB-03 & CATCCCCCTG \\
OPB-04 & GGACTGGAGT \\
OPB-05 & TGCGCCCTTC \\
OPB-06 & TGCTCTGCCC \\
OPB-07 & GGTGACGCAG \\
OPB-08 & GTCCACACGG \\
OPB-09 & TGGGGGACTC \\
OPB-10 & CTGCTGGGAC \\
\hline
\end{tabular}


Figure.1 Amplification of Parents (Male and Female) and F1 with Opa-5 Primer ("L" Represents Ladder Dna, "M" Represents Male Parent, "F" Represents Female Parent and "F1" Represents F1 Offspring or Hybrid)

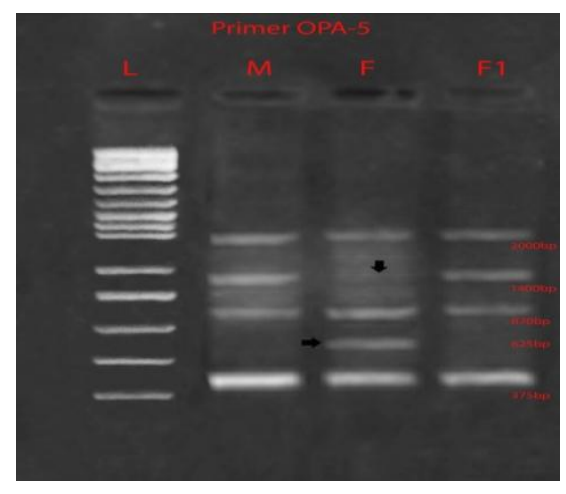

Figure.2 Amplification of Parents (Male and Female) And F1 with Opb-9 Primer ("L" Represents Ladder Dna, "M" Represents Male Parent, "F" Represents Female Parent and "F1" Represents F1 Offspring or Hybrid)

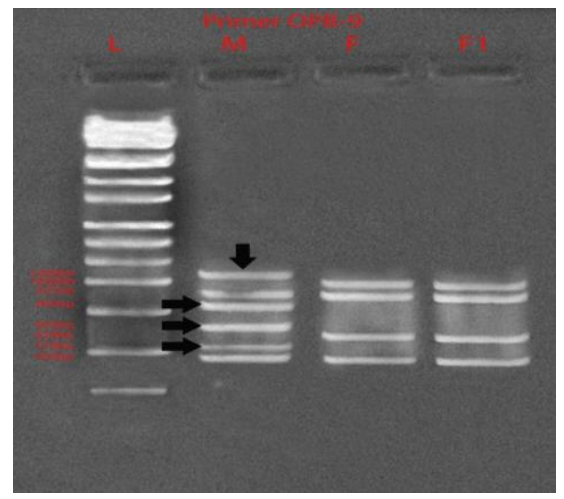

Figure.3 Amplification of Parents (Male and Female) and F1 with Opa-7 Primer ("L" Represents Ladder Dna, "M" Represents Male Parent, "F" Represents Female Parent and "F1" Represents F1 Offspring or Hybrid)

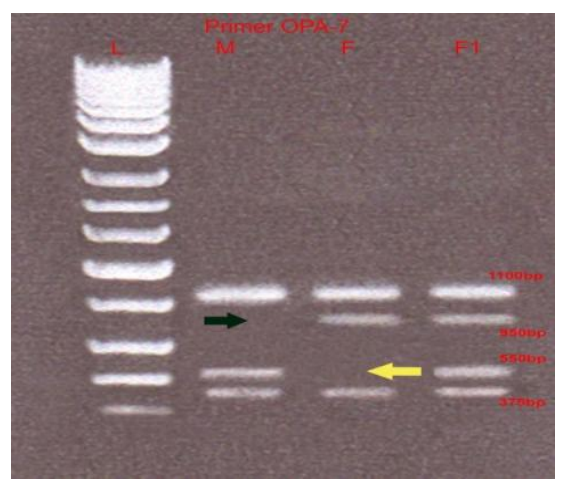


Figure.4 Hybrid Testing with Opa-7 Primer in Seed Lot 6 (S) ("L" Represents Ladder Dna, "M" Represents Male Parent, "F" Represents Female Parent, "F1" Represents F1 Offspring or Hybrid, "S8 to S100" Represents Individual Plant in Seed Lot 6 and Arrow Mark Showing

Missing Band Represents Off Types)

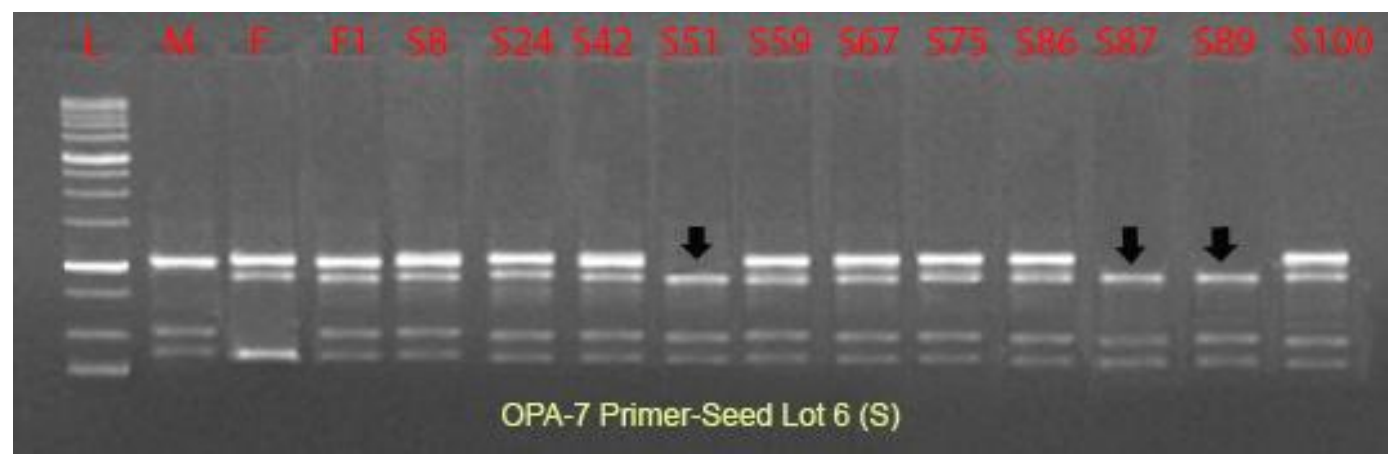

Figure.5 Hybrid Testing with Opa-7 Primer in Seed Lot 14 (T) ("L" Represents Ladder Dna, "M" Represents Male Parent, "F" Represents Female Parent, "F1" Represents F1 Offspring or Hybrid, "T1 To T100" Represents Individual Plant in Seed Lot 14 and Arrow Mark Showing Missing Band Represents Off Types)

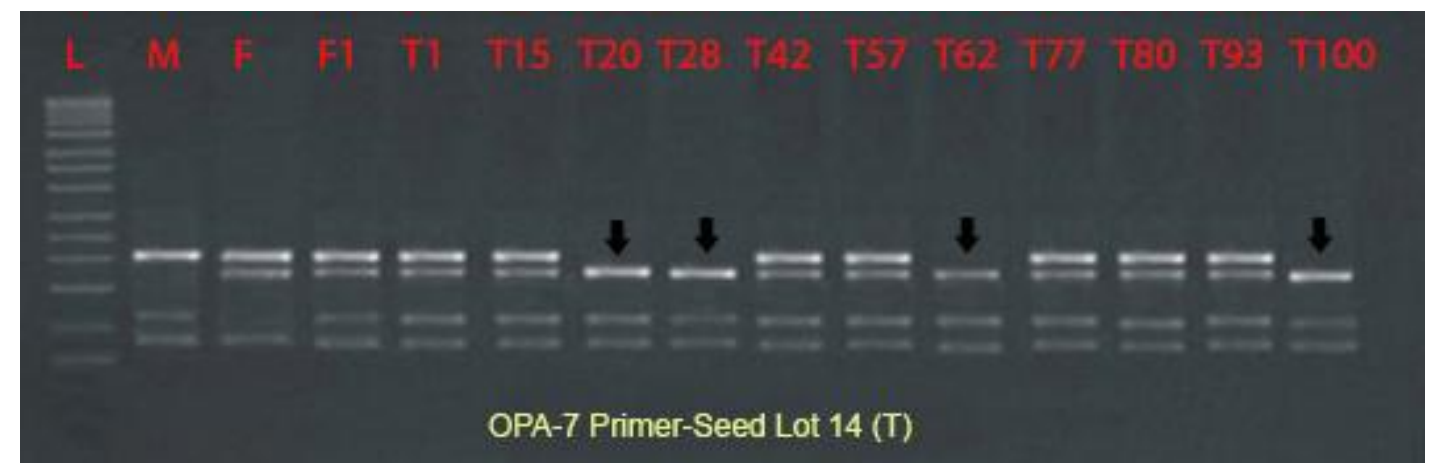

Figure.6 Hybrid Testing with Opa-7 Primer In Seed Lot 31 (U) ("L” Represents Ladder Dna, "M" Represents Male Parent, "F" Represents Female Parent, "F1" Represents F1 Offspring or Hybrid, "U5 to U100" Represents Individual Plant in Seed Lot 31 and Arrow Mark Showing Missing Band Represents off Types)

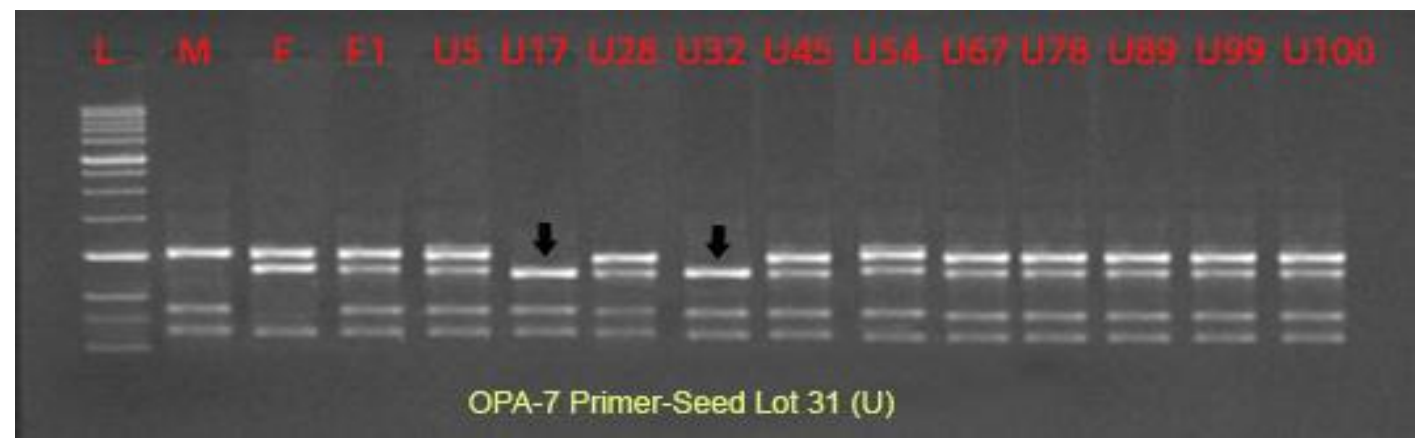


There was less reports in tobacco parents and its hybrid identification and their usage in genetic purity of tobacco hybrids and with RAPD markers it is the first report in India. Thirty SSR markers were used by Katarina et al (2010) for identification of ten Macedonia tobacco varieties in which twenty four SSR were used for identification of Macedonia tobacco varieties like Prilep varieties (4); broad-leaf varieties (2) and Yaka and Djebel varieties (4). Similarly with twelve ISSR primers forty tobacco cultivars showed polymorphism by Edrisi et al (2012). Samizadeh et al (2013) were reported genetic diversity in eighty nine flue-cured tobacco varieties with twelve ISSR markers, in which UBC817, UBC824 and UBC873 were useful for tobacco cultivars identification. Sarala and Rao (2008) reported genetic diversity in eight FCV tobacco varieties (Hema, VT 1158, Hemadri, Kanthi, CM 12, Kanchan, Bhavya and FCV Special) and two burley cultivars (Banket-A1 and BSRB-II) with twenty four RAPD primers, in which ten primers showed $100 \%$ polymorphism that can be useful for variety identification.

Similarly in other crops there are number of reports of varietal identification and genetic purity of F1 hybrids. Rom et al (1995) identified three tomato parents and their hybrids with four RAPD primers and they have used these primers for genetic purity testing. Yadav et al (2001) assessed genetic purity in DCH-32 cotton hybrid and their parental lines using RAPD markers and field GOT both showed similar results. Rao et al (2001) were reported genetic purity in twenty four pearl millet genotypes (A, B, R lines) and their seven hybrids with thirty one RAPD primers in which four RAPD primers (OPA-4, OPA-18, OPA-12 and OPB-18) were helpful for detection of twenty four genotypes and they were suitable for hybrid analysis. Liu et al (2007a) reported genetic purity in two hundred and twenty eight cabbage hybrid seeds with male and female parent specific two RAPD, two ISSR and one SSR primers and observed eight selfed and off type plants with both molecular and field grow out trials (GOT). Sangeeta et al (2011) tested seven RAPD for characterization of DCH-32 cotton hybrid and its parents, in which three primers distinguish F1 hybrid from its parental lines.

Similarly in other crop like tomato (Liu et al., 2007b; Ilbi et al., 2004), corn (Andreoli et al., 2006), capsicum (Mongkolporn et al., 2004), maize (Bakari 2015), rice (Santhy et al., 2003; Sayyed et al., 2009; Galal et al., 2014), cotton (Vamadevaiah et al., 2006; Rajput et al., 2007); Dongre and Parkhi, 2005; Ashok et al., 2011), cucumber (Li et al., 2008), oil palm (Satish and Mohankumar, 2007), radish (Man and Joo, 2009), carrot (Grzebelus et al., 2001),

Tea (Wan et al., 2014) parents specific and hybrid specific alleles were identified and these primers utilized for genetic purity of hybrids.

In the present study we have reported three polymorphic RAPD primers (OPA-5, OPB9 and OPA-7) out of twenty primers. OPA-5 primer is specific to female parent and OPB9 primer is specific to male tobacco parent. In our studies we have observed single primer OPA-7 that can distinguish both male parent, female parent and their hybrids. This primer OPA-7 was utilized for hybrid purity testing against hybrid seed lots (1-50), in which few plants in seed lot 6,14 and 31 were observed off types due to the mixture of other cultivars. This RAPD primer can access the genetic purity in hybrid seed lots which does not require any field grow out tests and in seed level it can detect the percentage of purity. 


\section{References}

Abdel, M.A.L., Ahmed, M.M.M. and Ali, B.A. 2006. Application of molecular markers for hybrid maize (Zea mays L.) identification. Journal of Food, Agriculture \& Environment. 4 (2): 176-178.

Amrapali, A.A., Sakhare, S.B., Kulwal, P.L., Dhumale, D.B. and Abhilasha, K. 2008. RAPD profile studies in Sorghum for identification of hybrids and their parents. International Journal of Integrative Biology. 3(1): 18.

Andreoli, C., Carvalho, C.C. and Andirade, R.V. 2006. Yield losses due to inbreeding and the use of molecular marker (RAPD) for assessment of genetic purity in hybrid corn (Zea mays L.). Revista Brasileira-deMilho-e-Sorgo. 5(1): 1-14.

Ashok, B.D., Mamta, P.R., Manoj, R.B. and Kshanada, J.M. 2011. Identification and genetic purity testing of cotton F1 hybrid using molecular markers. Indian journal of Biotechnology. 10, 301-306.

Bakari, A.M. 2015. Assessment of seed genetic purity of hybrid maize variety UH6303 in southern highlands of Tanzania by random amplified polymorphic DNA (RAPD) markers. African Journal of Agricultural Research. 10(30): 2911-2918.

Ballester, J. and Vicente, M.C.de. 1998. Determination of F1 hybrid seed purity in pepper using PCR-based markers. Euphytica. 103, 223-226.

Del, P.L., Abet, M., Sorrentino, C., Acanfora, F., Cozzolino, E. and Di, M.A. 2000. Genetic variability in Nicotiana tabacum and Nicotiana species as revealed by RAPD procedure. Beiträge zur tabakforshung. Int. Contrib. Tobacco
Res. 19, 1-15.

Dongre, A. and Parkhi, V. 2005. Identification of cotton hybrid through the combination of PCR based RAPD, ISSR and microsatellite markers. J. Plant Biochem. Biotechnol. 14, 53-55.

Doyle, J.J. and Doyle, J.L. 1990. Isolation of plant DNA from fresh tissue. Focus. $12,13-15$.

Edrisi, M.K., Samizadeh, L.H. and Shoaei, D.M. 2012. Assessing the genetic diversity of tobacco (Nicotiana tabacum L.) varieties. Crop Breeding Journal. 2(2): 125-132.

Galal, O.A., Mahmoud, I.A.Y., Mona, A., Ahmed, T.G. and Said, A.D. 2014. Assessment of genetic purity of some hybrid rice parental lines using protein profile and fertility restorer gene linked markers. International Journal of Biotechnology Research. 2(6): 75-88.

Grzebelus, D., Senalik, D., Jagosz, B., Simon, P.W. and Michalik, B. 2001. The use of AFLP markers for the identification of carrot breeding lines and F1 hybrids. Plant Breeding. 120(6): 526-528.

Ilbi, H., Waters, C.M. and Bolkan, H.A. 2004. Sequence extension of RAPD markers to increase their utility for hybrid purity testing in tomato. Seed Sci. Technol. 32, 197-203.

Joseph, J.K., James, M.B. and Michael, J.H. 1998. Variability for Restriction Fragment Length Polymorphism's (RFLPs) and Relationships among Elite commercial Inbred and virtual Hybrid onion populations. J. Amer. Soc. Hort. Sci. 123(6): 1034-1037.

Katarina, D., Ivana, M., Kiril, F., Ognen, S. and Georgi, D.E. 2010. Genetic Variability of Macedonian Tobacco Varieties determined by Microsatellite Marker Analysis. 
Diversity. 2, 439-449.

Kumar, P., Gupta, V.K., Misra, A.K., Modi, D.R. and Pandey, B.K. 2009. Potential of molecular markers in Plant Biotechnology. Plant Omics Journal. 2(4): 141-162.

Li, X., Liu, L., Gong, Y., Wang, Y., Fu, B., Hou, X., Zhu, X., Yu, F. and Shen, H. 2008. Molecular testing of cucumber hybrid genetic purity with RAPD marker. Seed Sci. Technol. 36, 440446.

Liu, L., Yan, W., Yi-Qin, G., Tong-Min, Z., Guang, L., Xiao-Yan, L. and FanMin, Y. 2007b. Assessment of genetic purity of tomato (Lycopersicon esculentum L.) hybrid using molecular markers. Scientia Horticulturae. 115(1): 7-12.

Liu, L., Guang, L., Yiqin, G., Wenhao, D., Yan, W., Fanmin, Y. and Yunying, R. 2007a. Evaluation of Genetic Purity of F1 Hybrid Seeds in Cabbage with RAPD, ISSR, SRAP, and SSR Markers. Hortscience. 42(3):724-727.

Man, K.H. and Joo, S.C. 2009. Seed purity test and genetic diversity evaluation using RAPD markers in Radish (Raphanus sativus L.). Korean Journal of crop sciences. 54(4): 346350.

McDonald, MB., Elliot, L.J. and Sweeney, P. 1994. DNA extraction from dry seeds for RAPD analysis in varietal identification studies. Seed Sci. Technology. 22, 171-176.

Mongkolporn, O., Dokmaihom, Y., Kanchana, C. and Pakdeevraporn, P. 2004. Genetic purity test of hybrid capsicum using molecular analysis. $J$. Hortic. Sci. Biotechnol. 79(9): 449451.

Nicolas, S., James, N.D.B., Sonia, O., Nicolas, B., Lucien, B., Adrian. W., Simon, G., Manuel, C.P. and Nikolai, V.I. 2014. The tobacco genome sequence and its comparison with those of tomato and potato. Nature Communications. 5, 1-9.

Patrick, S.S. and Roger, P.W. 1998. The molecular basis of Cytoplasmic male sterility and fertility restoration. Trends in Plant Sciences. 3(5): 175180.

Rajaput, H.J., Patil, R.B. and Shinde, S.M. 2007. Biochemical and molecular characterization of cotton hybrids. Ann. Plant Physiol. 21(1): 51-54.

Rao, K.S.S., Varies, A., Mohapatra, T., Kumari, K.A. and Sharma, S.P. 2001. Electrophoresis of seed esterase and RAPD analysis for identification of hybrids and parental lines of pearl millet (Pennisetum glaccum L.). Plant Varieties and Seeds. 14(1): 4152.

Rom, M., Bar, M., Rom, A., Pilowsky, M. and Gidoni, D. 1995. Purity control of F1 hybrid tomato cultivars by RAPD markers. Plant Breed. 114, 188-190.

Samizadeh, L.H., Mohsenzadeh, G.M., Edrisi, M.K., Shoaeid, D.M. and Aalami, A. 2013. Assessing the genetic diversity of 89 flue-cured tobacco varieties using morphological traits and inter-simple sequence repeat markers. Crop Breeding Journal. 3(2): 79-85.

Sangeeta, I.M., Biradarpatil, N.K., Hanchinal, R.R., Vyakaranahal, B.S., Janagoudar, B.S. and Katageri, I.S. 2011. Characterization of DCH-32 cotton hybrid and parental lines by SDS-PAGE and RAPD marker. Karnataka Journal of Agricultural Sciences. 24(3): 396-399.

Santhy, V., Dadlani, M., Mohapatra, T. and Sharma, S.P. 2003. Identification of the parental lines and hybrids of rice (Oryza sativa L.) using RAPD markers. Seed Sci.Technol. 31(1): 
187-192.

Sarala, K. and Rao, R.V.S. 2008. Genetic diversity in Indian FCV and burley tobacco cultivars. Journal of Genetics. 87(2): 159-163.

Sathish, D.K. and Mohankumar, C. 2007. RAPD markers for identifying oil palm (Elaeis guineensis Jacq.) parental varieties (dura \& pisifera) and the hybrid tenera. Indian Journal of Biotechnology. 6, 354-358.

Sayyed, H.H., Sayyed, A.M.M., Ghorban, A.N. and Ahmad, A. 2009. Identification of rice hybrids using microsatellite and RAPD markers. African Journal of Biotechnology. 8(10): 2094-2101.

Vamadevaiah, H.M., Katageri, I.S., Anita, B., Thippeswamy, S. and Soregaon, C.D. 2006. Identification of RAPD markers in genetic purity test of DHH-11 intrahirsutum hybrid. Ann. Biol. 22(2): 107-111.
Wan, P.F., Lyndel, W.M., Hua-Wei, T., Lin, Z., Sue, M. and Dapeng, Z. 2014. Varietal identification of tea (Camellia sinensis) using nanofluidic array of single nucleotide polymorphism (SNP) markers. Horticulture Research. 1, 14035.

Welsh, J. and McClelland, M. 1990. Fingerprinting genomes using PCR with arbitrary primers. Nucl Acids Res. 18, 7213-7218.

Williams, J.G.K., Kubelik, A.R., Livak, K.J., Rafalski, J.A. and Tingey, S.V. 1990. DNA polymorphism amplified by arbitrary primers are useful as genetic markers. Nucleic Acids Res. 18, 6531-6535.

Yadav, M., Ranade, R., Vaidya, U.J., Gopalakrishna, T. 2001. Genetic purity determination of cotton hybrid DCH-32 by random amplified polymorphic DNA (RAPD). Plant Varieties and Seeds. 14(1): 35-40.

\section{How to cite this article:}

Satish Kumar, D., and Kalyani, D. 2016. Genetic Purity of Flue Cured Tobacco F1 Hybrid with RAPD Markers. Int.J.Curr.Microbiol.App.Sci. 5(2): 557-566.

doi: http://dx.doi.org/10.20546/ijcmas.2016.502.063 